Check for updates

Cite this: Phys. Chem. Chem. Phys., 2018, 20, 15086

Received 1st February 2018, Accepted 29th April 2018

DOI: $10.1039 / \mathrm{c} 8 \mathrm{cp} 00760 \mathrm{~h}$

rsc.li/pccp

\title{
Amorphous phase state diagrams and viscosity of ternary aqueous organic/organic and inorganic/organic mixtures $\nmid$
}

\author{
Aleksandra Marsh, (D) a Sarah Suda Petters, (D) $\ddagger^{\mathrm{b}}$ Nicholas Ernest Rothfuss, (D) ${ }^{\mathrm{c}}$ \\ Grazia Rovelli, iD a Young Chul Song, ${ }^{a}$ Jonathan Philip Reid iD a and \\ Markus Dirk Petters (iD *c
}

\begin{abstract}
A Dimer Coagulation, Isolation and Coalescence $(\mathrm{DCIC})$ technique is used to probe the phase behaviour and glass transition temperatures of ternary aerosol mixtures. The DCIC technique is used to perform temperature and relative humidity dependent viscosity measurements at viscosities near $5 \times 10^{6} \mathrm{~Pa} \mathrm{~s}$. Measurements include organic-organic and organic-inorganic mixtures composed of sucrose-citric acid and sucrose-sodium nitrate. The data reported here add additional insight into the wide discrepancies in glass transition temperatures reported for pure sodium nitrate. The phase diagram model used in the work of Rothfuss and Petters (Phys. Chem. Chem. Phys., 2017, 19, 6532-6545) is expanded to include multiple solute components. Data and model predictions of the mixtures are in good agreement with the modified model. These measurements are compared with values from Holographic Optical Tweezer (HOT) measurements taken at room temperature. Overall, the viscosities determined from the DCIC and HOT techniques are in good agreement.
\end{abstract}

\section{Introduction}

A significant fraction of ambient submicron non-refractory aerosol mass can be attributed to organic components. ${ }^{1}$ The organic fraction evolves through functionalisation, fragmentation and oligomerisation reactions, ${ }^{2}$ can become internally mixed with inorganic aerosol components and responds to changes in relative humidity $(\mathrm{RH})$ by absorbing/desorbing water. The oxidation of volatile organic compounds in the gas phase leads to sufficiently high molecular weight/low volatility compounds to form secondary organic aerosol (SOA). Recent studies suggests that SOA can exist in a highly viscous or even an amorphous solid phase, with significant implications for aerosol light interactions in the atmosphere, cloud droplet and

\footnotetext{
${ }^{a}$ School of Chemistry, University of Bristol, Bristol, BS8 1TS, UK

${ }^{b}$ Department of Atmospheric Science, Colorado State University, Fort Collins, 80523-1371, CO, USA

${ }^{c}$ Department of Marine, Earth, and Atmospheric Sciences, North Carolina State University, Raleigh, 26795-8208, NC, USA.E-mail: markus_petters@ncsu.edu $\dagger$ Electronic supplementary information (ESI) available: The supplement contains description of water activity models, surface tension models, and tabulated data of the DCIC and HOT measurements. All experimental data presented in the figures are also provided through the University of Bristol data repository at J. P. Reid et al. (2018). See DOI: 10.1039/c8cp00760h

\# Present address: Department of Environmental Sciences and Engineering, Gillings School of Global Public Health, The University of North Carolina at Chapel Hill, Chapel Hill, 27599-7431, NC, USA.
}

ice crystal formation, and further heterogeneous chemical processing. ${ }^{3-8}$ A number of studies report that SOA can have a viscosity between $10^{4}-10^{9} \mathrm{~Pa} \mathrm{~s}$ at ambient temperatures, dependent on SOA formation conditions, i.e. the identity of the precursor volatile organic compound, and both the concentration of the VOC and $\mathrm{RH} .{ }^{7-10}$ This range in viscosity suggests that semi-solid viscosities may be relatively common, particularly at the lower temperatures found in the middle and upper troposphere. ${ }^{11,12}$ Aerosol viscosity influences diffusion constants of molecules within a particle, ${ }^{8,13,14}$ rates of heterogeneous reaction, ${ }^{15}$ the photodegradation of molecules within an aerosol particle $^{16}$ and the apparent volatility of the aerosol components. ${ }^{15}$ In addition, highly viscous particles may shield reactive species in the particle bulk, allowing for enhanced long-range transport of environmental contaminants. ${ }^{17,18}$

Under dry conditions, aerosol composition can achieve supersaturated states with respect to solute concentration, existing in a metastable non-crystalline amorphous or subcooled liquid form. ${ }^{19}$ Consequently, aerosol-based techniques are a necessity for measuring the viscosity of the amorphous, metastable states formed in supersaturated aerosol. This is challenging for a number of reasons including the small sizes of aerosol particles $(1 \mathrm{~nm}-10 \mu \mathrm{m})$, the wide range in accessible viscosity to a metastable phase $\left(10^{-3} \text { to }>10^{12} \mathrm{~Pa} \mathrm{~s}\right)^{13,20}$ and the often extremely small sample volumes derived from sampling techniques ( $\mu \mathrm{g}$ to $\mathrm{mg}$ ). As a result, the majority of the 
approaches available for measuring aerosol viscosity are indirect, such as the poke-and-flow technique ${ }^{21}$ and fluorescence lifetime imaging in which viscosity is inferred from the fluorescence lifetime of a molecular rotor. ${ }^{22-25}$ Despite these experimental challenges, it is now apparent that the addition of functional groups and increasing molecular weight are generally consistent with increasing viscosity. ${ }^{4,26,27}$ Numerous studies have now linked increasing viscosity with progressive oxidation using $\mathrm{OH}$ radicals or ozonolysis. ${ }^{22,28-31}$ In order to rationalise the behaviour of more chemically complex atmospheric organic particles, laboratory studies have used highly oxygenated species, such as sucrose and citric acid, as proxies for viscous SOA. ${ }^{32}$ For these systems, a decrease in relative humidity $(\mathrm{RH})$ has been shown to suppress the rate of semi-volatile organic loss, reaction rates or uptake of gaseous species, indicative of a concomitant increase in viscosity. ${ }^{15,33,34}$

Aerosol coalescence techniques have been developed to infer particle viscosity, where the time-dependence of the shape of the coagulated dimer can be related to the viscosity. ${ }^{35}$ Direct measurements of particle $(3-6 \mu \mathrm{m})$ viscosity can be made using Holographic Optical Tweezers (HOT) via the coalescence of two optically confined particles. ${ }^{27,35}$ Two different analysis approaches are employed dependent on the viscosity regime. At low viscosity, the elastically back scattered light may be used to determine particle viscosity with coalescence occurring on the 10 's $\mu$ s timescale. For coalescence events with particles of viscosity higher than $\sim 1 \mathrm{~Pa}$ s, brightfield imaging reveals the relaxation in shape directly, with the timescale for relaxation used to determine viscosity. ${ }^{35}$ Pajunoja et al. ${ }^{36}$ use a variant of the dimer coalescence technique, where naturally coagulated SOA aerosol are impacted onto a thin layer of carbon, and the degree of coalescence is analysed using scanning electron microscopy. ${ }^{36}$ Further, Zhang et al. ${ }^{37}$ determine the viscosity of secondary organic material that coagulated during particle formation and growth, by measuring the shape factor change via measuring particle electrical mobility and particle mass. ${ }^{37}$ Rothfuss and Petters ${ }^{38}$ prepare and isolated dimers $\sim 100 \mathrm{~nm}$ in diameter using a dimer coagulation, isolation, and coalescence (DCIC) technique where dimers are produced by coagulation of oppositely charged particles followed by removal of uncoagulated particles via electrostatic filtration. ${ }^{38,39}$ The DCIC technique can be used to measure the temperature dependence of viscosity and the temperature dependence of the $\mathrm{RH}$ range where viscosity transitions from $1 \times 10^{6}$ to $3 \times 10^{7} \mathrm{~Pa}$ s. The primary advantage of this technique is the ability to infer the temperature dependence of the viscosity and potentially extrapolate the measurements to estimate glass transition temperatures. Data for sucrose aerosol determined with the submicron size DCIC technique were consistent with super-micron size HOT coalescence technique by Power et al. ${ }^{20,35,40}$

Using the DCIC approach, a phase diagram model for binary aqueous sucrose has been proposed by Rothfuss and Petters ${ }^{38}$ using a modified Vogel-Fulcher-Tammann equation, the Gordon-Taylor mixing rule, and a mass based hygroscopicity model. Here, we extend this model to multicomponent systems and test the model with two ternary model systems, aqueous mixtures of sucrose-citric acid and sucrose-sodium nitrate. The viscosity of these mixed component aerosol systems can be expected to transition across the sensitive range of the DCIC measurement approach making them appropriate model systems. Indeed, the measurements presented here are the first study in which the viscosity of ternary mixtures are measured and compared using both the DCIC and HOT coalescence techniques at different temperatures and relative humidities. The DCIC technique is used to probe the phase behaviour and glass transition temperatures of the ternary aerosol mixtures. The coagulated dimer measurements are compared with a limited number of mixture data points from HOT measurements, which provide an absolute measure of aerosol viscosity and provide additional viscosity data at $22{ }^{\circ} \mathrm{C}$. Such measurements on mixtures of increasingly complex composition are crucial to determine if the properties of mixtures can be treated purely as additive, based on data from binary component mixtures, or if a more complex interplay of component interactions is required to predict the properties of mixtures. ${ }^{20,38,39}$ Further, this study provides more data on the influence of an added inorganic component on mixture viscosity, for comparison with previous work of Power et al. who examined the aqueous sucrose- $\mathrm{NaCl}$ ternary system as well as the appropriate binary aerosol. ${ }^{20}$

\section{Experimental methods}

\section{II.a DCIC experimental method}

This experimental setup and dimer coalescence technique has been extensively discussed in previous publications. However, the experimental set up utilised in this work differs slightly from the previous literature and the modified instrument design is shown in Fig. 1..$^{26,38,39}$ Aerosol was generated using a dual syringe pump system feeding two constant output atomisers (TSI 3076), generating two separate aerosol streams, which are then passed through two sets of tandem Nafion dryers (PD-50T24MSS, PermaPure). The two streams of dried aerosol are then passed through ${ }^{210} \mathrm{Po}$ radiation sources to yield equilibrium distributions of charged particles before injection into two separate differential mobility analysers (DMA), a TSI-DMA (TSI 3071) and a high flow DMA referred to as the HFDMA. ${ }^{41,42}$ As depicted in Fig. 1, the TSI-DMA is connected to a power supply applying a negative bias potential and, hence, selects positively charged particles. The HFDMA is connected to a power supply applying a positive bias potential and selectively filters for particles of negative polarity. Both the TSI-DMA and HFDMA were configured to produce a stream of $80 \mathrm{~nm}$ aerosol and operated with sheath-to-sample flow ratios of $3 \mathrm{~L} \mathrm{~min}^{-1}: 1.5 \mathrm{~L} \mathrm{~min}{ }^{-1}$.

After the DMAs, additional drying was implemented via the use of one or more cold traps positioned within each size selected stream. In all experiments, the two dried, size selected streams of aerosol were routed through two separate $12^{\prime \prime}$ long, $1 / 2^{\prime \prime}$ outer diameter stainless steel tubes positioned on a cold plate (ThermoElectric Cooling America AHP-1200CV) set to a temperature of $-30{ }^{\circ} \mathrm{C}$. When further drying was necessary, a second set of identical tubes were also positioned inline; 


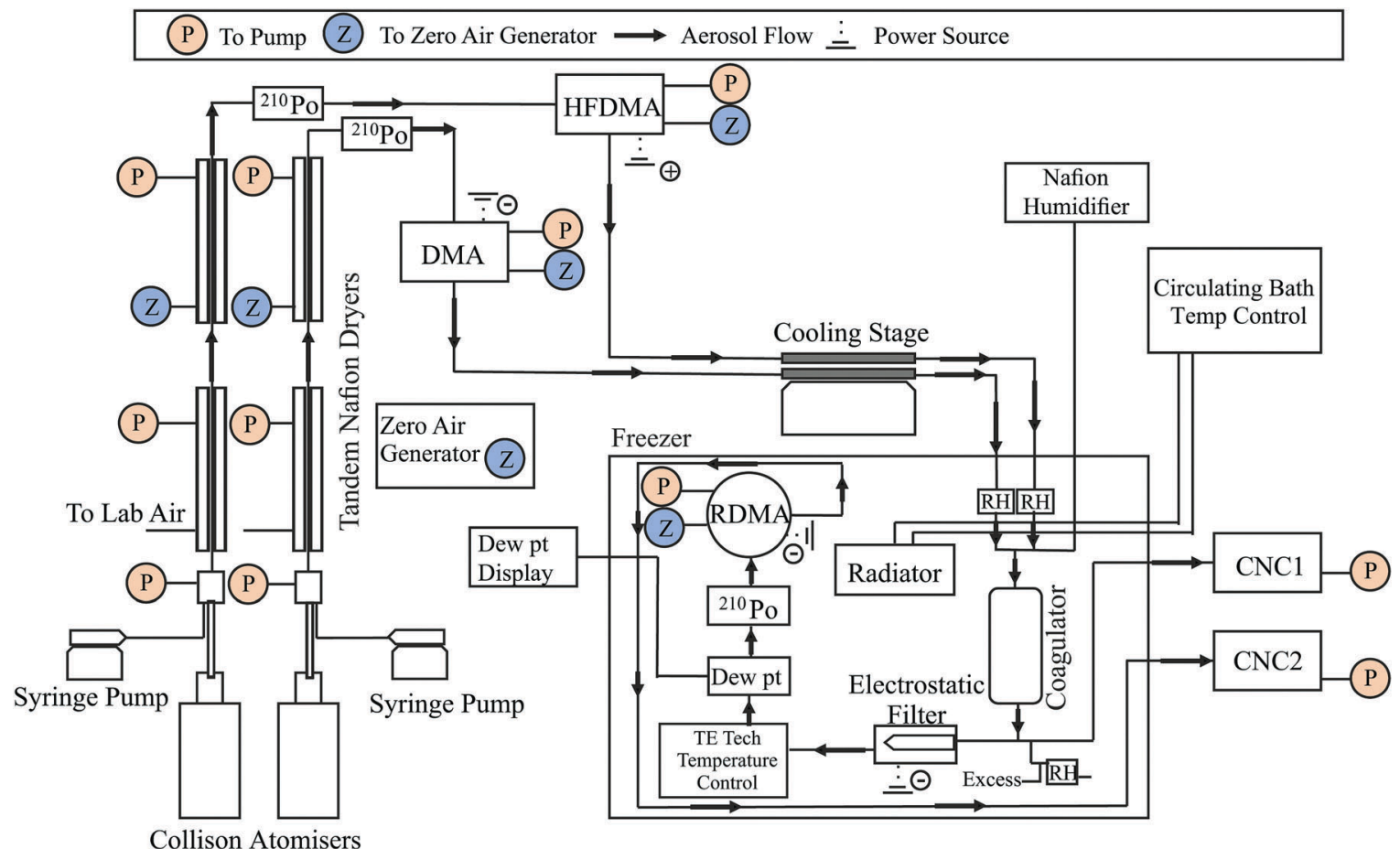

Fig. 1 Schematic of the DCIC technique. (DMA - Differential Mobility Analyser, HFDMA, High Flow Differential Mobility Analyser, RDMA - Radial Differential Mobility Analyser, CNC - Condensation Nuclei Counter, RH - relative humidity sensor ${ }^{210}$ Po - polonium 210 alpha radiation source). Note pumps to atomisers are not vacuum pumps.

these tubes were inserted between blocks of dry ice $\left(-79{ }^{\circ} \mathrm{C}\right)$. Next, the two dry aerosol streams enter a commercial chest freezer which housed most of the remaining instrument elements. The freezer temperature could be controlled between $-25{ }^{\circ} \mathrm{C}$ and $+30{ }^{\circ} \mathrm{C}$ using a chilled bath circulator (Thermo Scientific C40P) interfaced with a heat exchanger placed inside the freezer. The temperature inside the freezer is referred to as the system temperature, and this value is tabulated alongside the measurement results (ESI $\dagger$ ). The aerosol streams were combined inside the freezer (for the first time) in a coagulator tube (approximate residence time of 5-6 s with $3 \mathrm{~L} \mathrm{~min}^{-1}$ flow rate). An optional third port introduces particle-free pre-humidified air into the coagulator. This flow was generated by routing particle-free zero air (Teledyne model 701) through a Nafion membrane submerged in a temperature controlled water bath. A combination of flow rate (0-1 $\left.\mathrm{L} \mathrm{min}^{-1}\right)$ and temperature adjustment of the Nafion water bath $\left(0-25{ }^{\circ} \mathrm{C}\right)$ was used to control the dew-point temperature inside the coagulator.

After exiting the coagulator, a flow of $0.3 \mathrm{~L} \mathrm{~min}^{-1}$ was diverted to monitor the total particle concentration measured using a condensation nuclei counter (TSI 3020) operated in bulk scattering mode. This measurement was used to monitor stability of the particle generation system. A second flow, also $0.3 \mathrm{~L} \mathrm{~min}^{-1}$, was routed through an electrostatic filter to remove all charged particles. The remaining neutral aerosol, comprising dimers from coagulation of oppositely charged particles and particles that spontaneously discharge en-route between the DMA and the coagulator, then pass through a temperaturecontrolled chamber. Temperature control was achieved using a thermal conditioner (temperature control unit) which is a Peltier-type thermoelectric heat exchanger (CP-200TT, TE Technology) and the temperature reached by the temperature control unit was measured using a thermistor (TE Technology MP-3193). Residence time in the loop was $5 \mathrm{~s}$. A chilled-mirror dew point hygrometer (General Eastern Optisonde) was used to determine the water vapour concentration in the gas-phase.

The charge neutral particles exiting the electrostatic filter were brought to charge equilibrium using another ${ }^{210}$ Po radiation source. The size distribution was measured using a radial $\mathrm{DMA}^{43}$ (RDMA, sheath-to-sample flow ratio 2:0.3 $\mathrm{L} \mathrm{min} \mathrm{min}^{-1}$ ) operated in scanning mobility particle sizer mode. ${ }^{44}$ The particle count from RDMA monodisperse output was measured using a second condensation nuclei counter (TSI 3020) operated in pulse counting mode. Data reduction from the RDMA output is as described in Rothfuss and Petters, ${ }^{38}$ and involves peak fitting to find the mode diameter of the dimer size distribution.

In a few positions throughout the instrument shown in Fig. 1, the RH was measured using temperature and humidity sensors (Rotronic HygroClip2). However, the RH used for data analysis was the water vapour concentration measured by the Dew Point Hygrometer and the RH was determined by the ratio of the vapour pressure and saturation vapour pressure evaluated at the temperature inside the conditioning loop using the parameterizations of Murphy and Koop, (eqn (8) and (10)). ${ }^{45}$

Experiments can be separated into two distinct types: isothermal humidification and heating cycles performed under dry conditions. These experiment types are detailed in 
Rothfuss and Petters. ${ }^{39}$ Briefly, isothermal humidification experiments fix the temperature of the temperature control unit inside the freezer, while slowly raising the water vapour content through the humidification line until the dimers relax to a spherical shape on the timescale of the measurement. In contrast, heating cycle experiments are performed under dry conditions (corresponding to the lowest dew-point that can be achieved with drying and the baseline system temperature inside the freezer), raising the temperature of the temperature control unit inside the freezer until the dimers relax to a spherical shape on the measurement timescale.

Some differences between the present experiments and the referenced work are summarized below. In isothermal humidification experiments, the humidified flow and the two size-selected particle flows were merged simultaneously via a Swagelok cross piece positioned at the inlet of the coagulation chamber; by contrast, the humidified flow was first introduced into the outflow of the TSI-DMA in the cited work. Additionally, under some circumstances the humidifier itself was bypassed, directing up to $1.2 \mathrm{~L} \mathrm{~min}^{-1}$ of zero air directly into the system. This was sometimes necessary at colder temperatures because the minimum conditioner RH value facilitated by the Nafion dryers and cold traps was not low enough to fully resolve the fully uncoagulated dimer mobility diameter. In heating cycle experiments the temperature control unit was sufficient.

The measured SMPS mode diameters from an isothermal humidification scan or a temperature scan are converted to the particle geometry factor $\xi$ using the expression given by Rothfuss and Petters (2016),

$$
\begin{gathered}
\xi=\frac{3}{D_{\mathrm{uc}} / D_{\mathrm{c}}-1}\left(\frac{D_{\mathrm{p}}}{D_{\mathrm{c}}}+\frac{D_{\mathrm{uc}} / D_{\mathrm{c}}-4}{3}\right) \\
\xi=1+\frac{3}{1+\exp \left[-k\left(\mathrm{RH}-\mathrm{RH}_{\mathrm{r}}\right)\right]}
\end{gathered}
$$

where $D_{\mathrm{p}}$ is the SMPS peak diameter, $D_{\mathrm{uc}}$ the fully uncoalesced and $D_{\mathrm{c}}$ is the fully coalesced dimer diameters. An example of the resulting experimental data as a function of $\mathrm{RH}$ is reported for an isothermal humidification in Fig. 2. The solid black line represents a fit to eqn (2). In eqn (2) $k$ is a steepness parameter, $\mathrm{RH}$ is the measured $\mathrm{RH}$ from the dew point hygrometer and $\mathrm{RH}_{\mathrm{r}}$ is the relative humidity representative of the midpoint of coalescence relaxation. For the heating cycle measurement, the terms $\mathrm{RH}$ and $\mathrm{RH}_{\mathrm{r}}$ are replaced with $T$ and $T_{\mathrm{r}}$, respectively where $T_{\mathrm{r}}$ is representative of the temperature at which the midpoint of coalescence relaxation occurs, and $T$ is the temperature measured by the temperature control unit.

Mapping from dimer mobility diameter to viscosity is based on the numerical procedure described Rothfuss and Petters. ${ }^{39}$ The relationship takes into account the monomer diameter, the residence time in the temperature control unit where relaxation takes place and the surface tension of the particle. For $80 \mathrm{~nm}$ monomers and conditioner residence time of $5 \mathrm{~s}$, measurements of $\mathrm{RH}_{\mathrm{r}}$ and $T_{\mathrm{r}}$ correspond to a viscosity of $\sim 5 \times 10^{6} \mathrm{~Pa} \mathrm{~s}$, which is slightly modified by potential changes in surface tension with composition. Both the DCIC and HOT coalescence

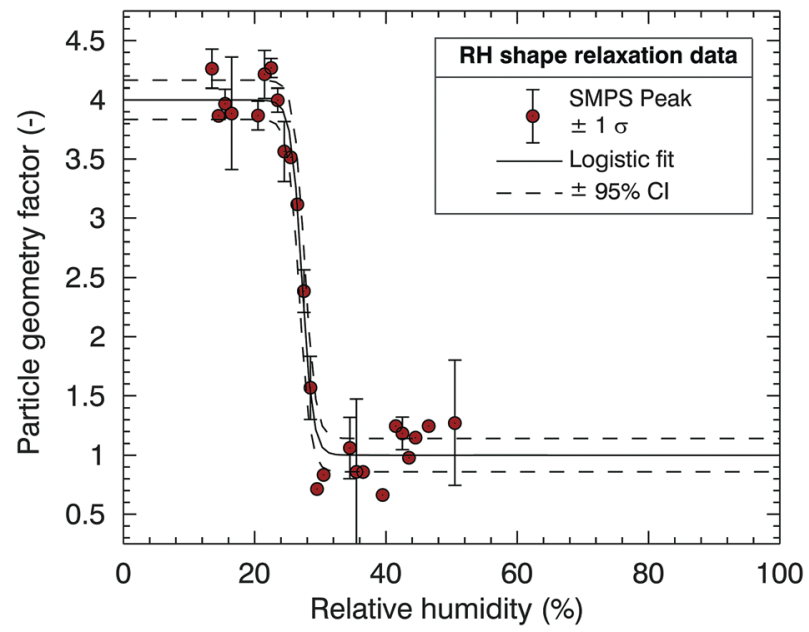

Fig. 2 Processed DCIC RH scan for a 80:20 sucrose-sodium nitrate mixture relaxing at $T=10{ }^{\circ} \mathrm{C}$. Data were binned in $1 \% \mathrm{RH}$ intervals. Error bars correspond to \pm 1 standard deviation of the number of scans in that bin. Lines show a logistic fit and the $95 \%$ confidence interval. Viscosity is inferred from the fit as a function of $\mathrm{RH}$.

technique require an estimate of surface tension to compute viscosity. A number of methods have been derived for combining surface tensions of simple binary solutions to estimate the surface tensions of complex mixtures at variable $\mathrm{RH}^{46,47}$ In this manuscript we consider ternary mixture surface tensions which have been determined using E-AIM Model $\mathrm{III}^{47}$ and parametrisation for surface tension values used have been provided in the $\operatorname{ESI} \dagger(\mathrm{S} .2)$.

The following chemicals were used. Citric acid (Sigma Aldrich $\geq 99.5 \%$ ACS Reagent), sucrose (Sigma Aldrich $\geq 99.5 \%$ BioXtra) and sodium nitrate (Sigma Aldrich $\geq 99.0 \%$ BioXtra). Aqueous solutions for atomization were prepared with HPLC grade water at a total solute concentration of $0.5 \mathrm{~g} \mathrm{~L}^{-1}$. Isothermal humidification measurements are presented at 0,5 , and $10^{\circ} \mathrm{C}$, whereas heating cycles allow for the determination of the temperature of dimer coalescence $\left(30-85{ }^{\circ} \mathrm{C}\right)$ under approximately dry conditions $(\sim 0 \% \mathrm{RH})$.

\section{II.b HOT experimental method}

The DCIC measurements are compared with a limited number of viscosity measurements using holographic optical tweezers (НOT). The HOT technique has been thoroughly described in previous publications. ${ }^{27,35}$ Thus, it is only briefly discussed here as the implementation was consistent with our earlier work. These measurements provide the dependence of viscosity on $\mathrm{RH}$ at $22{ }^{\circ} \mathrm{C}$ (ambient temperature). A gradient force optical trap is formed by tightly focusing a laser $(532 \mathrm{~nm}$, Laser Quantum Opus $3 \mathrm{~W}$ ) through a microscope objective with a high numerical aperture. This trapping beam is split using a Hamamatsu spatial light modulator (SLM, X10468) to form two optical traps. The RH of the trapping region is controlled using a ratio of dry and wet nitrogen gas and measured using a precell capacitance probe that is regularly calibrated (Honeywell, HIH-4202A). Optically confined droplets $(3-7 \mu \mathrm{m})$ equilibrate 
with the gas phase $\mathrm{RH}$ of the chamber. Droplet equilibration (e.g., stable droplet size) is monitored via stimulated Raman scattering appearing at wavelengths commensurate with whispering gallery modes and is used to retrieve droplet size and refractive index with an accuracy of $< \pm 2 \mathrm{~nm}$ and $< \pm 0.0005$ respectively. ${ }^{48}$ The two optically confined droplets are brought close enough together to coalesce. For droplets with a viscosity $>1 \mathrm{~Pa} \mathrm{~s}$, the timescale of coalescence is determined using direct brightfield imaging with a high frame rate camera (Vision Research, Phantom v. 7.3) with relaxation times $>10 \mathrm{~ms}$. Alternatively, for droplets with viscosity up to $100 \mathrm{mPa} s$ and relaxation timescales of $<1 \mathrm{~ms}$, elastic light scattering is used to determine the shape relaxation timescale which is then used to calculate the RH dependent viscosity. ${ }^{35,40}$

\section{Phase diagram model}

In this section, a model is introduced that can be used to represent isopleths of constant viscosity (eqn (3)-(7)) and provide a way of representing the $T$ and $\mathrm{RH}$ dependence of the viscosity of the ternary mixtures. All symbols are defined in Table 1 . The model is similar to that of Rothfuss and Petters ${ }^{38}$ who based this on the work of Berkemeier et al. ${ }^{49}$ Key differences to the previous version of the model include: first, the extension of the Gordon-Taylor equation and water activity model to multiple solute components; second, the treatment of water content dependent hygroscopicity parameters, $\kappa_{\mathrm{m}}$, and the definition of the Gordon-Taylor constants as the inverse $k_{i}=1 / k_{(\mathrm{GT}, i)}$ of that used previously. The inverse definition was introduced for simplicity.

$$
\begin{gathered}
w_{\mathrm{s}}=\left(1+\kappa_{\mathrm{m}}\left(a_{\mathrm{w}} /\left(1-a_{\mathrm{w}}\right)\right)\right)^{-1} \\
T_{\mathrm{g}}=\frac{\left(1-w_{\mathrm{s}}\right) T_{\mathrm{g}, \mathrm{w}}+w_{\mathrm{s}} \sum_{i} k_{i} \varepsilon_{i} T_{\mathrm{g}, i}}{1-w_{\mathrm{s}}\left(1-\sum_{i} k_{i} \varepsilon_{i}\right)} \\
T_{0}=T_{\mathrm{g}}-(B /(12-A)) \\
T=\left(B / \log _{10} \eta-A\right)+T_{0}
\end{gathered}
$$

Eqn (3) represents a mass based hygroscopicity parameter, $\kappa_{\mathrm{m}}$, determined using the total mass fraction of solute in the droplet, $w_{\mathrm{s}}$ and the water activity, $a_{\mathrm{w}}{ }^{50,51}$ The mass based hygroscopicity parameter for a mixture containing multiple solute components is determined using the $\kappa_{\mathrm{m}, i}$ of the individual components and the mass fraction of the $i$ th component in the dry particle, $\varepsilon_{i}$, as shown in eqn (4). Note that $a_{\mathrm{w}}=\mathrm{RH} /(100 \%)$ and the effect of particle surface curvature on the relative humidity at which the particle composition is equilibrated (the Kelvin effect) is not considered. ZSR mixing is assumed to model the water content of multicomponent mixtures. Eqn (5) introduces the GordonTaylor mixing rules for multiple dry solutes, which is re-arranged from eqn (4) in Koop et al. ${ }^{4}$

Eqn (6) is used to determine parameter $T_{0}$ that introduces a temperature dependence to the viscosity with slope and curvature parameters $(A, B)$ given by the VFT equation, $\log _{10} \eta=A+B /\left(T-T_{0}\right)$, and a dry glass transition temperature $T_{\mathrm{g}}$ defined by eqn (4). This is the same assumption made by Rothfuss and Petters. ${ }^{39}$ Eqn (7) is used to determine the temperature at which the particle has a viscosity, $\eta . A$ and $B$ represent fitted slope and curvature parameters describing the temperature dependence of viscosity determined by Rothfuss and Petters. ${ }^{39}$ Values uses to initialize the model are summarized in Table 2 . These values are taken from the literature or from this work. Values derived from this work are explained later in the text.

\section{Results and discussion}

Fig. 3(a) shows a heating cycle experiment for a dry 60:40 sucrose-sodium nitrate mixture. Fig. 3(b) shows how the shape factor data are used to derive particle viscosity inferred as a function of temperature. The calculations are based on Rothfuss and Petters ${ }^{38}$ and modified Frenkel theory ${ }^{60}$ and relate $\xi$ to $\eta$ via a lookup table. Calculations are performed for $\xi$ values computed from the logistic fit for $1<\xi<4$. The calculations assume a residence time of $5 \mathrm{~s}$ in the conditioner, a value for $D_{\text {mono }}=80 \mathrm{~nm}$, and a surface tension corresponding to an estimate for the aqueous mixture (Section S2 of the ESI $\dagger$ ). Also shown in Fig. 3(b) is the impact of the uncertainty in surface tension on the determination of particle viscosity. The green error bars indicate the maximum uncertainty in particle viscosity assuming a value for the surface tension in the range of $0.03<$ $\sigma<0.15 \mathrm{~J} \mathrm{~m}^{-2}$, circumscribing a generous range of possible values for surface tension of different compounds, ranging from low surface energy organic materials ${ }^{61}$ to high surface energy inorganic melts. ${ }^{62}$ The range demonstrates that the uncertainty on derived temperature for the $5 \times 10^{6} \mathrm{~Pa} \mathrm{~s}$ viscosity transition

Table 1 Notation for multicomponent phase diagram model, tabulated definition of all symbols used in eqn (3)-(7)

\begin{tabular}{ll}
\hline$A, B$ & $\begin{array}{l}\text { Fitted slope and curvature parameters describing the } \\
\text { temperature dependence of viscosity } \\
a_{\mathrm{w}}\end{array}$ \\
$\varepsilon_{i}$ & $\begin{array}{l}\text { Water activity of solution } \\
\kappa_{\mathrm{m}, i}\left(a_{\mathrm{w}}\right)\end{array}$ \\
$k_{i}$ & $\begin{array}{l}\text { Mass fraction of the } i \text { th component in the dry particle } \\
\text { solute, with parameterized dependence on water } \\
\text { content }\end{array}$ \\
$\begin{array}{l}\text { Binary Gordon-Taylor constant for the mixture of the } \\
\text { ith component with water }\end{array}$ \\
Particle viscosity
\end{tabular}

$T$

$T_{\mathrm{g}}$

$T_{\mathrm{g}, i}$

$T_{0}$

Temperature where the particle has viscosity $\eta$

Glass transition temperature of the mixed particle (water + dry solutes)

Glass transition temperature of $i$ th solute; $i=w$ denotes water Asymptotic temperature that produces a viscosity temperature dependence that has a slope and curvature parameters $(A, B)$ given by the VFT equation and a dry glass transition temperature $T_{\mathrm{g}}$

$w_{\mathrm{s}} \quad$ Total mass fraction of dry solutes in the particle. Also, $w_{\mathrm{s}} \stackrel{\mathrm{g}}{=} 1-w_{\mathrm{H}_{2} \mathrm{O}}$ 
Table 2 Parameters used for multicomponent phase diagram model predictions

\begin{tabular}{llll}
\hline \multicolumn{4}{l}{ Glass transition temperatures, $T_{\mathrm{g}, i}(\mathrm{~K})$} \\
\hline Water & Sodium nitrate & Citric acid & Sucrose \\
\hline $136^{a}$ & $292^{b}$ & $286^{d}$ & $341^{e}$ \\
& $220^{c}$ & & \\
\hline
\end{tabular}

Binary Gordon-Taylor constants, $k_{i}(-)$

\begin{tabular}{lll}
\hline Sodium nitrate/water & Citric acid/water & Sucrose/water \\
\hline $0.1667^{f}$ & $0.333^{g}$ & $0.1905^{h}$ \\
\hline
\end{tabular}

Binary hygroscopicity parameters, $\kappa_{\mathrm{m}, i}(-)$

\begin{tabular}{cll}
\hline Sodium nitrate/water & Citric acid/water & Sucrose/water \\
\hline$\sim 0.4^{i}$ & $\sim 0.25^{j}$ & $\sim 0.14^{k}$ \\
\hline
\end{tabular}

Temperature dependence for viscosity, VFT parameters

\begin{tabular}{ll}
\hline$A(-)$ & $B(\mathrm{~K})$ \\
\hline $1.1756^{l}$ & $172.01^{l}$
\end{tabular}

${ }^{a}$ Saleki-Gerhardt and Zografi. ${ }^{52}{ }^{b}$ Average value from Dette and Koop, ${ }^{53}$ extrapolated from DSC measurements with mixtures. ${ }^{c}$ Number of literature sources. ${ }^{54-58 d}$ This work, derived from DCIC T-scan with pure citric acid. ${ }^{e}$ Rothfuss and Petters, derived from DCIC T-scan with pure sucrose. ${ }^{39} f$ This work, inferred by fitting $T_{\mathrm{g}}$ data from DCIC T-scans of sucrose-sodium nitrate mixtures. ${ }^{g}$ This work, inferred by fitting $T_{\mathrm{g}}$ data from DCIC T-scans of sucrose-citric acid mixtures. ${ }^{h}$ Rothfuss and Petters, derived from glass transition data of sucrose water mixtures. ${ }^{39}{ }^{i}$ Derived from E-AIM model III. ${ }^{47}$ Value is varies with $a_{\mathrm{w}}$ and is parameterized accordingly (Table S1.1, ESI). ${ }^{j}$ Derived from Berkermeier et al. ${ }^{49}$ parameterization. Value is varying with $a_{\mathrm{w}}$ and is parameterized accordingly (Table S1.1, ESI). ${ }^{k}$ Derived from Zobrist et al. ${ }^{59}$ parameterization evaluated at $T=0{ }^{\circ} \mathrm{C}$. Value is varies with $a_{\mathrm{w}}$ and is parameterized accordingly (Table S1.1, ESI). ${ }^{l}$ Constant fitted to sucrose data by Rothfuss and Petters. ${ }^{39}$ due to the surface tension assumption is small. The range in modeled actual surface tensions for the different mixtures is slightly smaller and ranges between $0.06 \mathrm{~J} \mathrm{~m}^{-2}$ (pure citric acid) and $0.130 \mathrm{~J} \mathrm{~m}^{-2}$ (pure sodium nitrate melt). Modelled surface tension values are used for the analysis. The resulting uncertainty in the derived temperature transition due to the uncertainty of the model surface tension estimate of the mixture (ESI, $\uparrow$ S.2) is much smaller than the indication in figure in $3(\mathrm{~b})$. Further, the glass transition temperature is estimated by extrapolating the VFT fit to a viscosity corresponding to $10^{12} \mathrm{~Pa} \mathrm{~s}^{38}$ and shown in Fig. 3(b) by the purple point. The uncertainty of the extrapolation is estimated to be $\pm 10{ }^{\circ} \mathrm{C}$ based on results discussed later (Fig. 5). To date extrapolation from DCIC has only been applied to two cases where glass transition temperature is known, pure citric acid and pure sucrose. For both substances the error is within the $\pm 10{ }^{\circ} \mathrm{C}$ estimate.

Fig. 4 shows a typical dataset obtained from the HOT instrument; using coalescence measurements across a range of relative humidities, a parametrisation of the viscosity of the mixture can be generated. Measurements for mixed ternary aqueous sucrose-citric acid aerosol particles are compared with the previously published parameterisations of the simple binary systems. ${ }^{27}$ The parametrisations are generated using a polynomial fitting through the data points of viscosity collected using the HOT; the uncertainty associated with the parametrisation is a result of the uncertainty in fitting to the experimental data. In Fig. 4 each measurement (data point) for the 60 : 40 sucrose : citric acid mixture represents an experimentally determined viscosity from a single coalescence event. Data points are not shown for the binary aqueous-sucrose and aqueous-citric mixtures for overall figure clarity and because they are presented in the work of Song et al. ${ }^{27}$ For comparison with DCIC measurements, HOT measurements are all taken at
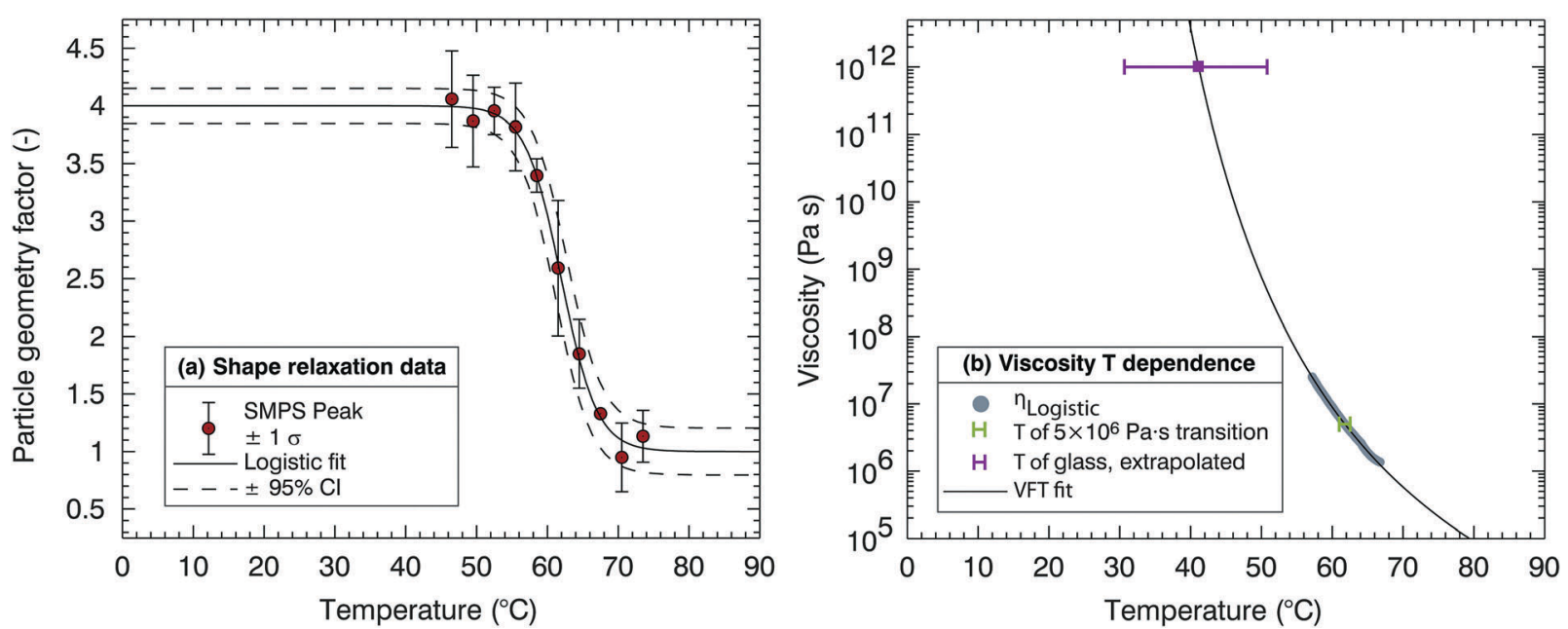

Fig. 3 Processed Dimer Coalescence and Isolation (DCIC) T-scan for a dry $60: 40$ sucrose : sodium nitrate mixture. In (a) SMPS peak data were binned in $3{ }^{\circ} \mathrm{C}$. Error bars correspond to \pm 1 standard deviation of the number of scans in that bin. Lines show a logistic fit (eqn (1)) and the $95 \%$ confidence interval. In (b) viscosity derived from logistic fit in left figure (grey points) at diameters falling between $\left[D_{\mathrm{uc}}-1 \mathrm{~nm}<D_{\mathrm{p}}<D_{\mathrm{c}}+1 \mathrm{~nm}\right]$. Solid line shows the VFT fit to the data, dashed lines the $95 \%$ confidence interval. The purple point shows the glass transition temperature that is estimated by extrapolating the VFT fit to $\eta=10^{12} \mathrm{~Pa}$. The green point corresponds to $T_{r}$, defined as the midpoint of the logistic fit or coalescence relaxation; the green error bars represent a range of surface tension values used to compute viscosity $\left(0.03<\sigma<0.15 \mathrm{~J} \mathrm{~m}^{-2}\right)$. 


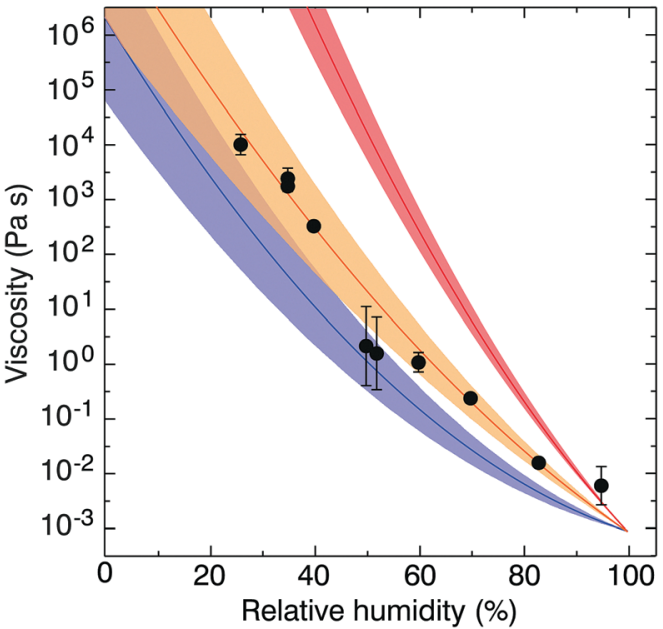

Fig. 4 Holographic optical tweezer (HOT) measurements of viscosity of a sucrose and citric acid mixture containing $60 \%$ and $40 \%$ by mass of each solute (black points) with an error envelope (orange). Parametrisations and error envelopes of binary aqueous sucrose (red) and binary aqueous citric acid (blue) viscosity are shown from Song et al. ${ }^{27}$

$22 \pm 2{ }^{\circ} \mathrm{C}$ and the corresponding $\mathrm{RH}_{\mathrm{r}}$ value at which the DCIC measurement is made is estimated assuming a viscosity of $5 \times 10^{6} \mathrm{~Pa}$ s. Advantageously, this technique provides measurements over a much wider range in viscosity than the DCIC technique. As a disadvantage, there is no temperature control, and this means that the HOT can provide an additional measurement only at room temperature. Coincidentally, the DCIC isothermal humidification experiments at room temperature are challenging due to the large amount of moisture that needs to be added. Thus the HOT data extends the temperature range for representing the viscous properties of the aerosol and complements the DCIC isothermal humidification approach.
Fig. 5(a) and (b) summarise the data taken in this study for heating cycles under constant dry conditions for the aqueous sucrose-citric acid mixtures. In Fig. 5(a) the values of temperature correspond to the temperature at which the viscosity of the mixture is $5 \times 10^{6} \mathrm{~Pa}$. The data show a gradual increase in the relaxation temperature with increasing sucrose mass fraction. The mixing rule is not linear in mass fraction space, though the convexity is relatively small.

The values in Fig. 5(b) correspond to the glass transition temperatures estimated from the modified VFT fit described in Fig. 3 from each cycle. Available literature values from Rothfuss and Petters ${ }^{26}$ for the binary aqueous-solute system (i.e. aqueoussucrose) are also shown here, with good agreement with the DCIC measurements and VFT model extrapolation. The data in Fig. 5(b) were used to construct a binary mixing model for the glass transition temperature of sucrose-citric acid mixtures, which is shown by the solid line. The model was obtained by a nonlinear least square fit to the data of the full model (eqn (5)-(6)). The fit was performed as follows. First glass transition temperatures for pure sucrose, pure citric acid and $k_{i}$ for sucrose/water (Table 2) are fixed. Next the RH in the model is set to zero. The remaining $k_{i}$ for citric acid/water is varied such that the error between the model and the data in Fig. 5(b) is minimized. Finally, the VFT parameters for pure sucrose are used to estimate the mixing rule for the relaxation temperature in Fig. 5(a). Therefore, the model lines in Fig. 5(a) and (b) are effectively a one parameter fit to a model whose remaining parameters were constrained from pure component data identified in the literature. The resulting model provides an acceptable representation of dry mixtures of sucrose and citric acid. Note that the scatter in the data relative to the model Fig. 5(b) is approximately twice as large as the scatter in Fig. 5(a), which is due to the added uncertainty introduced by the extrapolation of the data to $T_{\mathrm{g}}$ using the VFT fit. The excellent agreement of the model and data in Fig. 5(a) provide an encouraging first
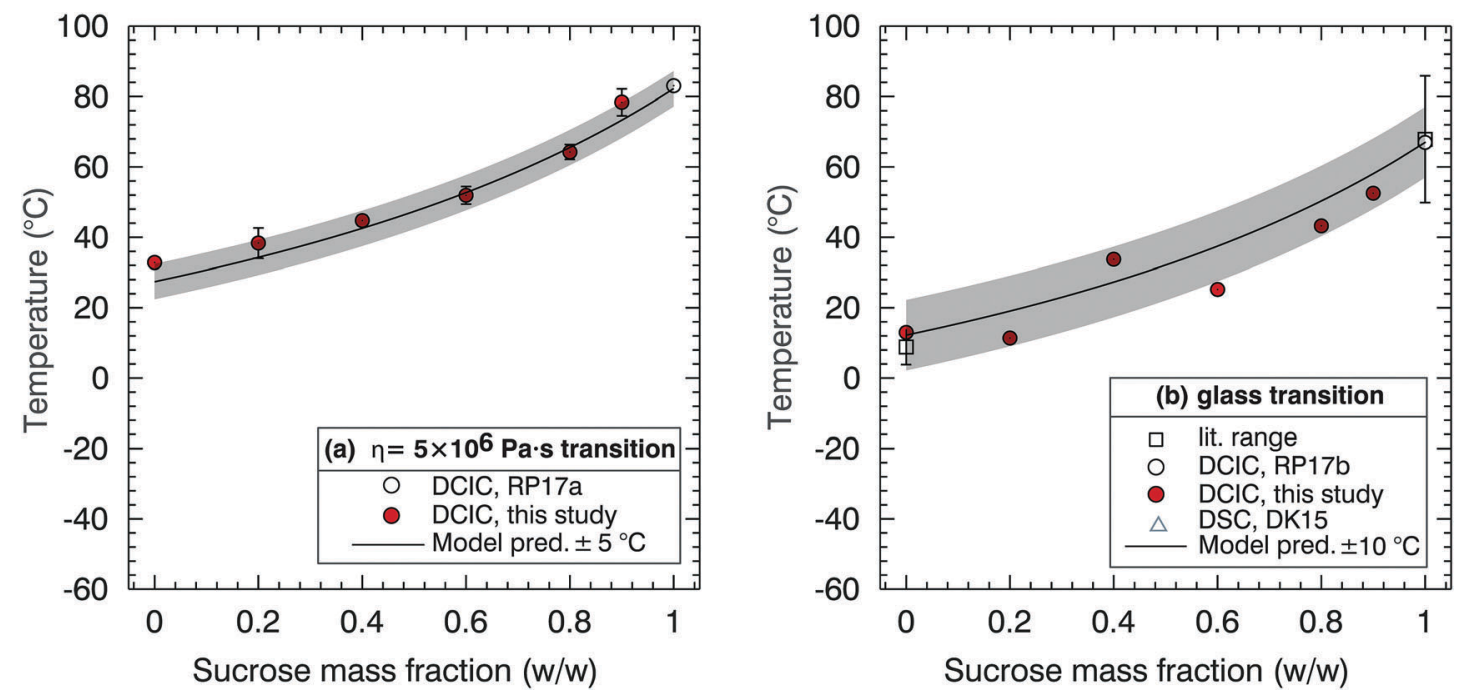

Fig. 5 Sucrose-citric acid mixtures. (a) Dependence of the $\eta=5 \times 10^{6} \mathrm{~Pa}$ s transition on sucrose mass fraction. (b) Dependence of glass transition temperature on sucrose mass fraction. References in the legend are Rothfuss and Petters denoted as RP17a ${ }^{39}$ and RP17b, ${ }^{38}$ respectively. In RP17a, ${ }^{39}$ the literature range refers to the range from multiple studies listed in their ESI, $\dagger$ and RP17b. ${ }^{38}$ 
validation of the model assumptions, since the data are fit to the extrapolated data in Fig. 5(b) and since pure component VFT data were applied to the mixture.

Fig. 6(a) and (b) are the corresponding plots to Fig. 5 but for the sucrose- $\mathrm{NaNO}_{3}$ mixtures. The fitting procedure to construct model lines is identical to that used for the sucrose/citric acid data shown in Fig. 5. Note that there is significant disagreement in the literature for the glass transition temperature for $\mathrm{NaNO}_{3}$. Measurements by Dette and Koop ${ }^{53}$ (open triangles in Fig. 6b) use differential scanning calorimetry (DSC) to determine the glass transition temperature of several organic/inorganic mixtures including sucrose and $\mathrm{NaNO}_{3}$. In their technique, aerosols are impacted on a surface and crystallisation is observed for several of the organic/inorganic mixtures considered. They report glass transition at $293 \mathrm{~K}$ and $287 \mathrm{~K}$, for pure $\mathrm{NaNO}_{3}$, equivalent to placing a limit of $10^{12} \mathrm{~Pa}$ s on the viscosity of $\mathrm{NaNO}_{3}$ under fully dry conditions at room temperature. ${ }^{53}$ However, this value of the glass transition temperature is not directly measured but is extrapolated from the values for the dry sucrose $/ \mathrm{NaNO}_{3}$ mixtures from a $\mathrm{NaNO}_{3}$ dry mass fraction of 0.8 .

In contrast, previous reports (open square in Fig. 6b) suggest that the glass transition temperature of sodium nitrate is in the range $216-225 \mathrm{~K},{ }^{54-58}$ considerably lower than the value suggested by Dette and Koop. ${ }^{53}$ Therefore, two models were constructed, one with $T_{\mathrm{g}}=292 \mathrm{~K}$ and one with $T_{\mathrm{g}}=220 \mathrm{~K}$. Either model can explain our observations.

DCIC measurements for sucrose mass fractions $<0.5$ were attempted. However, these particles were fully coalesced at room temperature. Suspecting a possible measurement artefact, these experiments were repeated several months later with a slightly reconfigured system. Repeated points at sucrose mass fraction 0.6 and 0.7 are in excellent agreement with the initial dataset. Again, no coalescence was observable for sucrose mass fraction $<0.5$ consistent with full coalescence on the measurement timescale. The DCIC technique requires the dimers to be sufficiently viscous at the cold/dry limit of the measurement scan to retain their hourglass shape. The fact that we could not produce DCIC data for sucrose mass fractions $<0.5$ is consistent with the cooler $T_{\mathrm{g}}$ model because otherwise we would expect viscosity to be higher and measurements to be feasible at higher $\mathrm{NaNO}_{3}$ fractions.

The DCIC measurements for sucrose mass fractions $<0.5$ were attempted for $\mathrm{RH}$ as low as $\sim 2 \%$. Baldelli et al. ${ }^{63}$ report a viscosity of $\sim 1 \mathrm{~Pa} \mathrm{~s}$ at a mass fraction water of $\sim 0.1$ for aqueous $\mathrm{NaNO}_{3}$, a composition approaching a pure liquid $\mathrm{NaNO}_{3}$ melt and corresponding to an $\mathrm{RH}$ of $24 \%$. Sucrose has a much higher viscosity in solution $\left(>10^{6} \mathrm{~Pa} \mathrm{~s}\right)$ at the same water mass fraction, ${ }^{27,35}$ which is what allowed us to measure viscosity for sucrose mass fractions $>0.5$. Note the 12 -order of magnitude difference reported for $\mathrm{NaNO}_{3}$ at room temperature, between $1 \mathrm{~Pa} \mathrm{~s}$ at an $\mathrm{RH}$ of $24 \%$ and $10^{12} \mathrm{~Pa}$ (glass transition) at an $\mathrm{RH}$ of $0 \%$. At $\mathrm{RH} \sim 2 \%$, DCIC measurements were not possible. Although this may be attributable to retained humidity in the coalescence chamber, these observations are also consistent with a viscosity of $\mathrm{NaNO}_{3}$ that remains lower than the $5 \times 10^{6}$ Pa s threshold at all $T$ and RH studied..$^{54-58,63}$ The discrepancy in estimated glass transition temperature of $\mathrm{NaNO}_{3}$ between near room temperature and $\sim 220 \mathrm{~K}$ has also been extensively discussed by Dette and Koop. ${ }^{53}$ They note a contradiction where in some cases atomized $\mathrm{NaNO}_{3}$ particles do not effloresce $^{64-68}$ and form amorphous particles with near zero water content at $0.05 \% \mathrm{RH}$, and in other cases efflorescence is observed. ${ }^{66-68}$ Dette and Koop ${ }^{53}$ argue that the inconsistency in $\mathrm{NaNO}_{3}$ efflorescence data could be consistent with a $T_{\mathrm{g}}$ near room temperature, with the ambient temperature of $290 \mathrm{~K}$ well below the melting point of crystalline $\mathrm{NaNO}_{3}$. However, a DSC measurement does not directly imply a viscosity. Given that the DSC and viscosity observations operate on different physical principles, the apparent discrepancy could indeed be explained with all cited observations being correct.
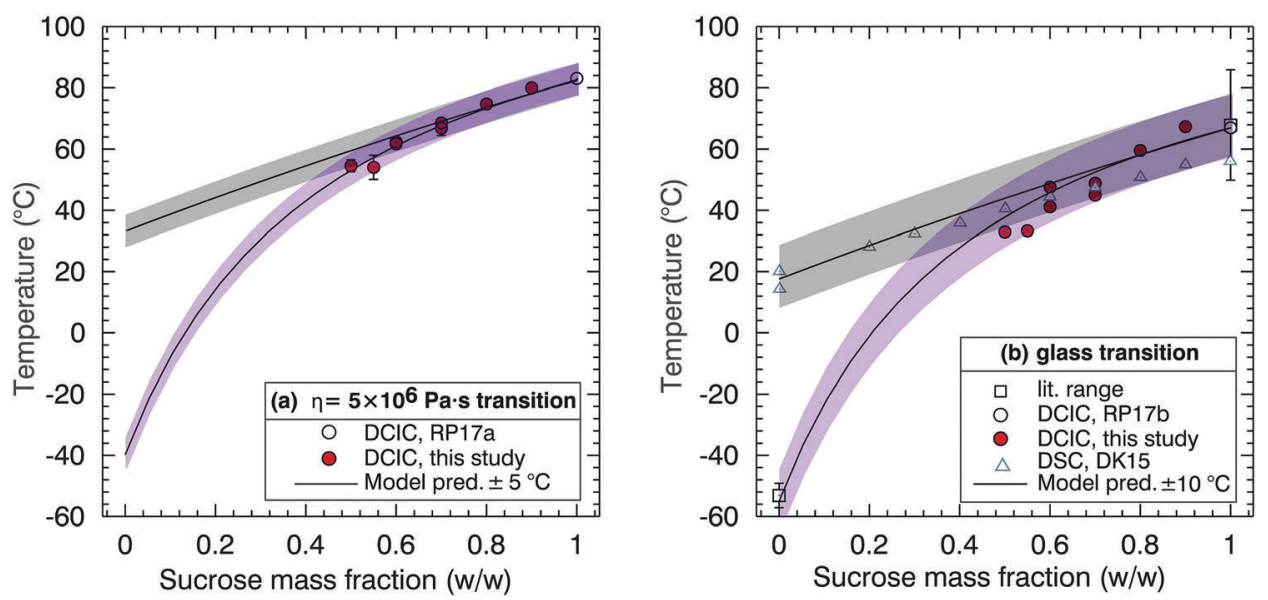

Fig. 6 Sucrose-sodium nitrate mixtures. (a) Dependence of the $\eta=5 \times 10^{6}$ Pa s transition on sucrose mass fraction. (b) Dependence of the glass transition temperature on sucrose mass fraction. References in the legend are Rothfuss and Petters, abbreviated as RP17a, where the literature range refers to the range from multiple studies listed in their ESI, $\dagger$ Dette and Koop abbreviated as DK15, ${ }^{53}$ and Rothfuss and Petters, abbreviated as RP17b. ${ }^{38}$ Data from Dette and Koop are from DSC measurements and were digitized from their Fig. $2 .{ }^{53}$ On (a) and (b) two model lines were constructed, one with $T_{\mathrm{g}}=292 \mathrm{~K}$ (grey) and one with $T_{\mathrm{g}}=220 \mathrm{~K}$ (purple). 


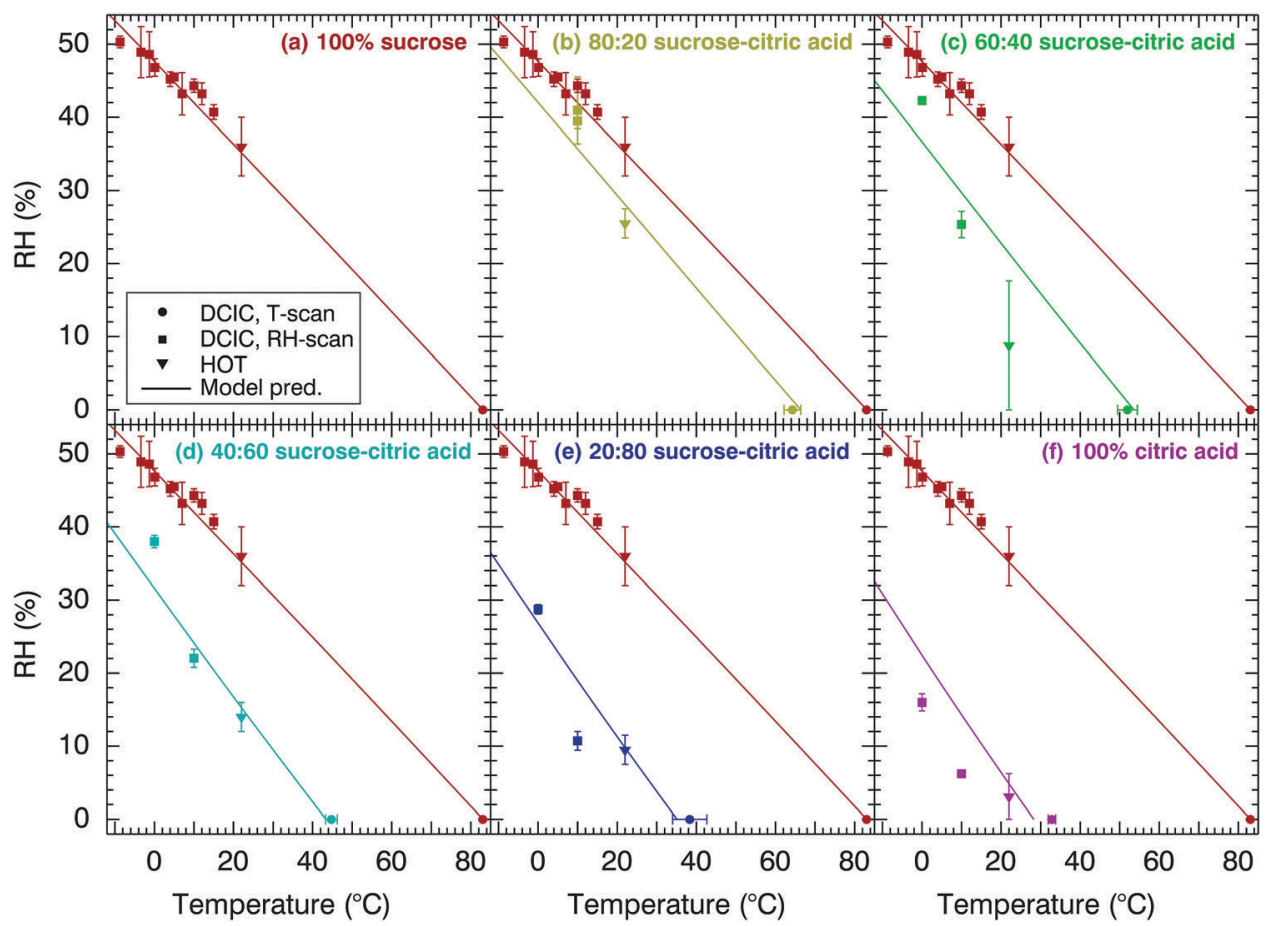

Fig. 7 Relationship between $T$, RH and $\eta=5 \times 10^{6} \mathrm{~Pa}$ s for mixtures of citric acid and sucrose with solutions listed combined with respect to mass percent. In (a) 100\% sucrose, (b) $80: 20$ sucrose-citric acid, (c) $60: 40$ sucrose-citric acid, (d) $40: 60$ sucrose-citric acid, (e) $20: 80$ sucrose-citric acid and (f) $100 \%$ citric acid. Solid line represents modified-VFT fit. Data for $100 \%$ sucrose are repeated in all panels and taken from Rothfuss and Petters ${ }^{39}$ and Power et al. ${ }^{40}$ Vertical and horizontal error bars for the DCIC technique correspond to the confidence interval of the logistic fit. Error bars associated with the HOT technique are discussed in the ESI. $\dagger$

Fig. 7 shows the relationship between $T$ and $\mathrm{RH}$ for a value of viscosity $5 \times 10^{6} \mathrm{~Pa}$ s for mixtures of citric acid and sucrose and for six different mixture compositions. Lines represent isopleths of constant viscosity $\left(5 \times 10^{6} \mathrm{~Pa} \mathrm{~s}\right)$ and the relationship between temperature and $\mathrm{RH}$, for the sucrose-citric acid, as determined from the modified VFT model. Data from both the DCIC temperature and RH scans are presented alongside additional measurements using the HOT technique at $22 \pm 2{ }^{\circ} \mathrm{C}$. For the DCIC measurements, the exact temperature of the $5 \times 10^{6} \mathrm{~Pa}$ s transition is recorded during the experiment. Error bars show the confidence interval of the fit for the DCIC measurements using eqn (1). For the HOT measurements, the RH-dependent viscosity is directly measured and used to generate a RH-dependent viscosity parametrisation (examples in Fig. 4). The error in the HOT measurement is determined from the range in $\mathrm{RH}$ values at a viscosity of $5 \times 10^{6} \mathrm{~Pa} \mathrm{~s}$, corresponding to that of the DCIC measurement. The large error for the HOT measurement in Fig. 7(c) is attributable to wide $\mathrm{RH}$ range at a comparable viscosity of $5 \times 10^{6}$ as shown in Fig. 4. Data for pure sucrose are taken from Rothfuss and Petters $^{39}$ and are shown for reference. Points at $\mathrm{RH}=0 \%$ are identical to those in Fig. 5(a).

The data in Fig. 7 show that the increase of the citric acid mixing fraction shifts the entire viscosity isopleth to colder temperatures and lower relative humidities. At dry conditions, the effect is due to the binary mixing of two substances with different $T_{\mathrm{g}}$ 's, as shown in Fig. 5 and 6 . At elevated $\mathrm{RH}$, the water content of the internally mixed particle is also altered by the changed hygroscopic response of the mixture. The net effect is predicted by the modified VFT model. We note that the modified VFT model was only constrained with data from Fig. 5 and material properties listed in Table 2 that have been previously reported. These values include water activity dependent surface tension and hygroscopicity parametrisations that are available in the ESI. $\dagger$ Thus, the agreement between the model and data is an independent test of the adequacy of the model framework for predicting the behaviour of ternary mixtures.

In Fig. 7, DCIC and HOT measurements for the sucrosecitric acid mixture are in reasonably good agreement with the model prediction. We believe that discrepancies between the data and the model are mostly caused by measurement errors that may be larger than those indicated by the error bars. For example, the RH measurement in the present version of the DCIC system is more uncertain when dewpoint temperatures that approach the limit of the dewpoint hygrometer $(-15$ to $-20{ }^{\circ} \mathrm{C}$ ). Similarly, the inference of the precise $5 \times 10^{6}$ Pa s from HOT measurements requires interpolation from a sometimes relatively noisy datasets as shown in Fig. 4 and the supplement of Rothfuss and Petters. ${ }^{39}$ However, model uncertainties also exist. Specifically, the location of the viscosity isopleth is sensitive to the hygroscopicity of the aerosol. ${ }^{39}$ The modelled hygroscopicity relies on accurate representation of the water activity $v s$. water content relationship for binary mixtures of water and solute below room temperature and in highly concentrated solutions. 
Such data are not widely available. In addition, the hygroscopicity of the mixed particle is represented by the ZSR mixing rule, ${ }^{69}$ which assumes that no solute-solute interactions exist. This assumption is likely questionable for these highly concentrated ternary mixtures. Finally, the conjecture that the VFT parameters $A$ and $B$ (Table 2), are only weakly dependent of solute composition over a wide range of compositions has not been rigorously evaluated. Failure of this assumption could lead to deviations between the model and the data. Considering these possible uncertainties, we conclude that the agreement between data and model is satisfactory. More ternary systems should be evaluated before the modified VFT model is more widely applied in atmospheric models.

Fig. 8 shows the relationship between $T$ and $\mathrm{RH}$ for a mixture with viscosity of $5 \times 10^{6} \mathrm{~Pa}$ s for mixtures of sucrose and $\mathrm{NaNO}_{3}$ at four different mixing fractions. The plot is constructed in the same manner as Fig. 7, with one difference. The modified VFT model is applied for $T_{\mathrm{g}, \mathrm{NaNO}_{3}}=220 \mathrm{~K}$ (solid line) and $T_{\mathrm{g}, \mathrm{NaNO}_{3}}=292 \mathrm{~K}$, (dashed lines), subsuming the two dry mixing models shown in Fig. 5. As would be expected, the difference between the two models increases with increasing $\mathrm{NaNO}_{3}$ mass fraction in the particle. The $T_{\mathrm{g}, \mathrm{NaNO}_{3}}=220 \mathrm{~K} \mathrm{model}$ is in better agreement with the data for the 70:30 and 60:40 mixture. We note that the model viscosity isopleth is also nonlinear for these mixtures. This non-linearity is caused by a strong dependence of on water activity for $\mathrm{NaNO}_{3}$ at low $\mathrm{RH}$ $(\mathrm{ESI}, \dagger \mathrm{S} .1)$. We note that no water activity $v s$. composition data is available for $\mathrm{RH}<10 \%$, and $\kappa_{\mathrm{m}}$ is assumed to be equal to the

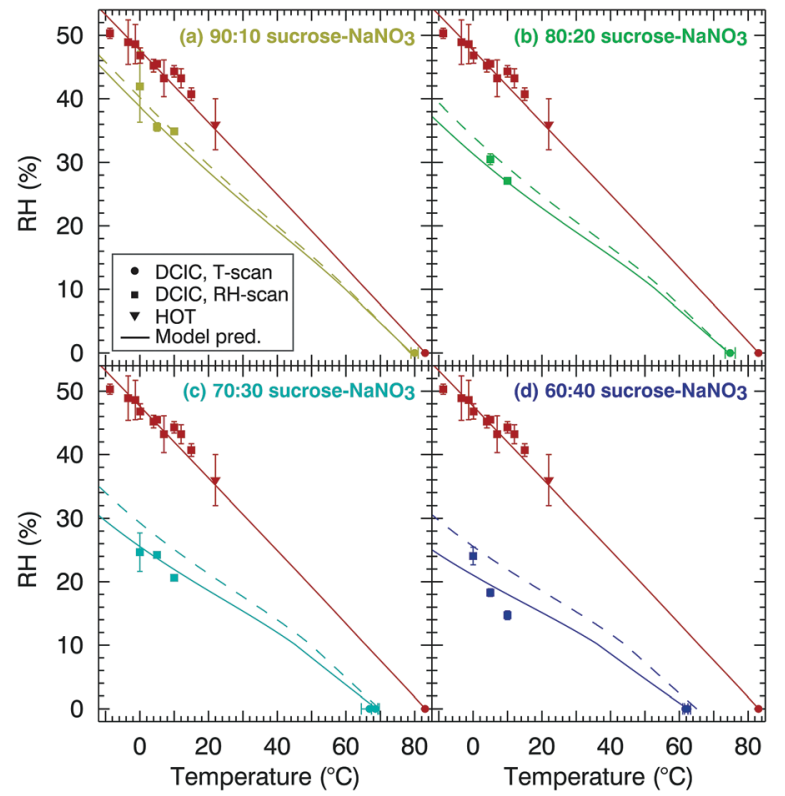

Fig. 8 Relationship between $T, \mathrm{RH}$ and $\eta=5 \times 10^{6} \mathrm{~Pa}$ s for mixtures of sodium nitrate and sucrose with solutions listed combined with respect to mass percent. In (a) $90: 10$ sucrose $-\mathrm{NaNO}_{3}$, (b) $80: 20$ sucrose $-\mathrm{NaNO}_{3}$, (c) $70: 30$ sucrose $-\mathrm{NaNO}_{3}$ and in (d) $60: 40$ sucrose $-\mathrm{NaNO}_{3}$. Solid line corresponds to a sodium nitrate $T_{\mathrm{g}}$ of $220 \mathrm{~K}$ and the dashed line corresponds to a sodium nitrate $T_{\mathrm{g}}$ of $292 \mathrm{~K}$. Red points are data for $100 \%$ sucrose taken from Rothfuss and Petters ${ }^{39}$ and Power et al. ${ }^{40}$ and are repeated in all panels for reference. value at $\mathrm{RH} 10 \%$ for this region of the phase diagram. The other caveats noted in the discussion of Fig. 7 also apply to the comparison between model observations for the sucrose- $\mathrm{NaNO}_{3}$ mixtures. Given these uncertainties, we consider the agreement of model and data encouraging, adding to the confidence that a properly constrained modified VFT model has potential to predict the viscosity isopleth for ternary mixtures over a wide range of $\mathrm{RH}$ and temperature.

\section{Conclusions}

Measurements are presented for sucrose-citric acid and sucrosesodium nitrate mixtures using the DCIC technique with complementary HOT measurements, which extend the accessible temperature range to $22{ }^{\circ} \mathrm{C}$. The modified VFT fit, GordonTaylor equation, and the mass based hygroscopicity parameter have been successfully applied to ternary mixtures. There is excellent agreement between experimental DCIC measurements and the modified-VFT model for the heating cycles measurements of sucrose-citric acid mixtures (Fig. 5 and 6) and satisfactory agreement for the isothermal humidification experiments (Fig. 7 and 8).

The viscosity and glass transition temperature for pure component sodium nitrate has been extensively discussed with available literature values of $T_{\mathrm{g}}=216-225 \mathrm{~K}^{54-58}$ and $T_{\mathrm{g}}=292 \mathrm{~K}$ extrapolated from DSC measurements reproduced from Dette and Koop. ${ }^{53}$ In summary, the viscosity of pure sodium nitrate is unlikely to reach a viscosity of $5 \times 10^{6} \mathrm{~Pa}$ s, the viscosity required for DCIC measurements. This conclusion is further corroborated by the better agreement between the modified-VFT fit to sucrose-sodium nitrate mixtures, using a $T_{\mathrm{g}}=220 \mathrm{~K}$, and the DCIC measurements presented in this manuscript. Further efforts are needed to link viscosity measurements, which measure the particles' resistance to flow, and glass transition temperature measurements, which probe to response of the material to heat flow. Finally, the successful application of the multicomponent phase diagram model to ternary solute component systems is encouraging and leaves room for further expansion to more compositionally complex solutions/ samples, including secondary organic aerosols.

\section{Conflicts of interest}

There are no conflicts to declare.

\section{Acknowledgements}

AM acknowledges EPSRC for DTA. JPR, MDP, NER and AM acknowledge NERC IOF grants NE/N013700/1 and NE/N006801/1. NER, SSP, and MDP acknowledge support from the United States Department of Energy, Office of Science, Biological and Environment Research, Grant number DE-SC 0012043. JPR and GR acknowledge NERC through funding from grant NE/N013700/1. The experimental data presented in the figures are provided through the University of Bristol data repository at Reid, J. P. (2018): DOI: 10.5523/bris.16u0rx4tgbgx31zkqx6gn25whb. 


\section{Notes and references}

1 J. L. Jimenez, M. R. Canagaratna, N. M. Donahue, A. S. H. Prevot, Q. Zhang, J. H. Kroll, P. F. DeCarlo, J. D. Allan, H. Coe, N. L. Ng, A. C. Aiken, K. S. Docherty, I. M. Ulbrich, A. P. Grieshop, A. L. Robinson, J. Duplissy, J. D. Smith, K. R. Wilson, V. A. Lanz, C. Hueglin, Y. L. Sun, J. Tian, A. Laaksonen, T. Raatikainen, J. Rautiainen, P. Vaattovaara, M. Ehn, M. Kulmala, J. M. Tomlinson, D. R. Collins, M. J. Cubison, E. J. Dunlea, J. A. Huffman, T. B. Onasch, M. R. Alfarra, P. I. Williams, K. Bower, Y. Kondo, J. Schneider, F. Drewnick, S. Borrmann, S. Weimer, K. Demerjian, D. Salcedo, L. Cottrell, R. Griffin, A. Takami, T. Miyoshi, S. Hatakeyama, A. Shimono, J. Y. Sun, Y. M. Zhang, K. Dzepina, J. R. Kimmel, D. Sueper, J. T. Jayne, S. C. Herndon, A. M. Trimborn, L. R. Williams, E. C. Wood, A. M. Middlebrook, C. E. Kolb, U. Baltensperger and D. R. Worsnop, Science, 2009, 326, 1525-1529.

2 K. C. Barsanti, J. H. Kroll and J. A. Thornton, J. Phys. Chem. Lett., 2017, 8, 1503-1511.

3 L. Renbaum-Wolff, J. W. Grayson, A. P. Bateman, M. Kuwata, M. Sellier, B. J. Murray, J. E. Shilling, S. T. Martin and A. K. Bertram, Proc. Natl. Acad. Sci. U. S. A., 2013, 110, 8014-8019.

4 T. Koop, J. Bookhold, M. Shiraiwa and U. Poschl, Phys. Chem. Chem. Phys., 2011, 13, $19238-19255$.

5 A. Virtanen, J. Joutsensaari, T. Koop, J. Kannosto, P. Yli-Pirila, J. Leskinen, J. M. Makela, J. K. Holopainen, U. Poschl, M. Kulmala, D. R. Worsnop and A. Laaksonen, Nature, 2010, 467, 824-827.

6 E. Jarvinen, K. Ignatius, L. Nichman, T. B. Kristensen, C. Fuchs, C. R. Hoyle, N. Hoppel, J. C. Corbin, J. Craven, J. Duplissy, S. Ehrhart, I. El Haddad, C. Frege, H. Gordon, T. Jokinen, P. Kallinger, J. Kirkby, A. Kiselev, K. H. Naumann, T. Petaja, T. Pinterich, A. S. H. Prevot, H. Saathoff, T. Schiebel, K. Sengupta, M. Simon, J. G. Slowik, J. Trostl, A. Virtanen, P. Vochezer, S. Vogt, A. C. Wagner, R. Wagner, C. Williamson, P. M. Winkler, C. Yan, U. Baltensperger, N. M. Donahue, R. C. Flagan, M. Gallagher, A. Hansel, M. Kulmala, F. Stratmann, D. R. Worsnop, O. Mohler, T. Leisner and M. Schnaiter, Atmos. Chem. Phys., 2016, 16, 4423-4438.

7 T. Yli-Juuti, A. Pajunoja, O.-P. Tikkanen, A. Buchholz, C. Faiola, O. Väisänen, L. Hao, E. Kari, O. Peräkylä, O. Garmash, M. Shiraiwa, M. Ehn, K. Lehtinen and A. Virtanen, Geophys. Res. Lett., 2017, 44, 2562-2570.

8 E. Abramson, D. Imre, J. Beranek, J. Wilson and A. Zelenyuk, Phys. Chem. Chem. Phys., 2013, 15, 2983-2991.

9 J. W. Grayson, Y. Zhang, A. Mutzel, L. Renbaum-Wolff, O. Böge, S. Kamal, H. Herrmann, S. T. Martin and A. K. Bertram, Atmos. Chem. Phys., 2016, 16, 6027-6040.

10 M. J. Song, P. F. F. Liu, S. J. Hanna, R. A. Zaveri, K. Potter, Y. You, S. T. Martin and A. K. Bertram, Atmos. Chem. Phys., 2016, 16, 8817-8830.

11 A. M. Maclean, C. L. Butenhoff, J. W. Grayson, K. Barsanti, J. L. Jimenez and A. K. Bertram, Atmos. Chem. Phys., 2017, 17, 13037-13048.
12 M. Shiraiwa, Y. Li, A. P. Tsimpidi, V. A. Karydis, T. Berkemeier, S. N. Pandis, J. Lelieveld, T. Koop and U. Poschl, Nat. Commun., 2017, 8, 15002.

13 M. Shiraiwa, M. Ammann, T. Koop and U. Pöschl, Proc. Natl. Acad. Sci. U. S. A., 2011, 108, 11003-11008.

14 H. C. Price, J. Mattsson and B. J. Murray, Phys. Chem. Chem. Phys., 2016, 18, 19207-19216.

15 F. H. Marshall, R. E. H. Miles, Y.-C. Song, P. B. Ohm, R. M. Power, J. P. Reid and C. S. Dutcher, Chem. Sci., 2016, 7, 1298-1308.

16 M. L. Hinks, M. V. Brady, H. Lignell, M. J. Song, J. W. Grayson, A. K. Bertram, P. Lin, A. Laskin, J. Laskin and S. A. Nizkorodov, Phys. Chem. Chem. Phys., 2016, 18, 8785-8793.

17 A. Zelenyuk, D. Imre, J. Beranek, E. Abramson, J. Wilson and M. Shrivastava, Environ. Sci. Technol., 2012, 46, 12459-12466.

18 M. Shrivastava, S. Lou, A. Zelenyuk, R. C. Easter, R. A. Corley, B. D. Thrall, P. J. Rasch, J. D. Fast, S. L. M. Simonich, H. Z. Shen and S. Tao, Proc. Natl. Acad. Sci. U. S. A., 2017, 114, 1246-1251.

19 U. K. Krieger, C. Marcolli and J. P. Reid, Chem. Soc. Rev., 2012, 41, 6631-6662.

20 R. M. Power, S. H. Simpson, J. P. Reid and A. J. Hudson, Chem. Sci., 2013, 4, 2597-2604.

21 J. W. Grayson, M. Song, M. Sellier and A. K. Bertram, Atmos. Meas. Tech., 2015, 8, 2463-2472.

22 A. Athanasiadis, C. Fitzgerald, N. M. Davidson, C. Giorio, S. W. Botchway, A. D. Ward, M. Kalberer, F. D. Pope and M. K. Kuimova, Phys. Chem. Chem. Phys., 2016, 18, 30385-30393.

23 N. A. Hosny, C. Fitzgerald, C. L. Tong, M. Kalberer, M. K. Kuimova and F. D. Pope, Faraday Discuss., 2013, 165, 343-356.

24 N. A. Hosny, C. Fitzgerald, A. Vysniauskas, A. Athanasiadis, T. Berkemeier, N. Uygur, U. Poschl, M. Shiraiwa, M. Kalberer, F. D. Pope and M. K. Kuimova, Chem. Sci., 2016, 7, 1357-1367.

25 C. Fitzgerald, N. A. Hosny, H. Tong, P. C. Seville, P. J. Gallimore, N. M. Davidson, A. Athanasiadis, S. W. Botchway, A. D. Ward, M. Kalberer, M. K. Kuimova and F. D. Pope, Phys. Chem. Chem. Phys., 2016, 18, 21710-21719.

26 N. E. Rothfuss and M. D. Petters, Environ. Sci. Technol., 2017, 51, 271-279.

27 Y. C. Song, A. E. Haddrell, B. R. Bzdek, J. P. Reid, T. Bannan, D. O. Topping, C. Percival and C. Cai, J. Phys. Chem. A, 2016, 120, 8123-8137.

28 T. Berkemeier, S. S. Steimer, U. K. Krieger, T. Peter, U. Poschl, M. Ammann and M. Shiraiwa, Phys. Chem. Chem. Phys., 2016, 18, 12662-12674.

29 J. F. Davies and K. R. Wilson, Chem. Sci., 2015, 1-8.

30 N. A. Hosny, C. Fitzgerald, A. Vyšniauskas, A. Athanasiadis, T. Berkemeier, N. Uygur, U. Pöschl, M. Shiraiwa, M. Kalberer, F. D. Pope and M. K. Kuimova, Chem. Sci., 2016, 7, 1357-1367. 31 S. S. Steimer, M. Lampimäki, E. Coz, G. Grzinic and M. Ammann, Atmos. Chem. Phys., 2014, 14, 10761-10772.

32 S. Bastelberger, U. K. Krieger, B. Luo and T. Peter, Atmos. Chem. Phys., 2017, 17, 8453-8471. 
33 G. Grzinic, T. Bartels-Rausch, T. Berkemeier, A. Turler and M. Ammann, Atmos. Chem. Phys., 2015, 15, 13615-13625.

34 J. F. Davies and K. R. Wilson, Chem. Sci., 2015, 6, 7020-7027.

35 R. M. Power and J. P. Reid, Rep. Prog. Phys., 2014, 77, 074601.

36 A. Pajunoja, J. Malila, L. Q. Hao, J. Joutsensaari, K. E. J. Lehtinen and A. Virtanen, Aerosol Sci. Technol., 2014, 48, i-iv.

37 Y. Zhang, M. S. Sanchez, C. Douet, Y. Wang, A. P. Bateman, Z. Gong, M. Kuwata, L. Renbaum-Wolff, B. B. Sato, P. F. Liu, A. K. Bertram, F. M. Geiger and S. T. Martin, Atmos. Chem. Phys., 2015, 15, 7819-7829.

38 N. E. Rothfuss and M. D. Petters, Aerosol Sci. Technol., 2016, 50, 1294-1305.

39 N. E. Rothfuss and M. D. Petters, Phys. Chem. Chem. Phys., 2017, 19, 6532-6545.

40 R. Power, D. L. Bones and J. P. Reid, Proc. SPIE, 2012, 8458.

41 M. Stolzenburg, N. Kreisberg and S. Hering, Aerosol Sci. Technol., 1998, 29, 402-418.

42 T. K. V. Nguyen, M. D. Petters, S. R. Suda, H. Guo, R. J. Weber and A. G. Carlton, Atmos. Chem. Phys., 2014, 14, 10911-10930.

43 S.-H. Zhang, Y. Akutsu, L. M. Russell, R. C. Flagan and J. H. Seinfeld, Aerosol Sci. Technol., 1995, 23, 357-372.

44 S. C. Wang and R. C. Flagan, Aerosol Sci. Technol., 1990, 13, 230-240.

45 D. M. Murphy and T. Koop, Q. J. R. Meteorol. Soc., 2005, 131, 1539-1565.

46 D. O. Topping, G. B. McFiggans, G. Kiss, Z. Varga, M. C. Facchini, S. Decesari and M. Mircea, Atmos. Chem. Phys., 2007, 7, 2371-2398.

47 C. S. Dutcher, A. S. Wexler and S. L. Clegg, J. Phys. Chem. A, 2010, 114, 12216-12230.

48 A. E. Haddrell, R. E. Miles, B. R. Bzdek, J. P. Reid, R. J. Hopkins and J. S. Walker, Anal. Chem., 2017, 89, 2345-2352.

49 T. Berkemeier, M. Shiraiwa, U. Pöschl and T. Koop, Atmos. Chem. Phys., 2014, 14, 12513-12531.

50 M. D. Petters and S. M. Kreidenweis, Atmos. Chem. Phys., 2007, 7, 1961-1971.
51 E. Mikhailov, S. Vlasenko, S. T. Martin, T. Koop and U. Poschl, Atmos. Chem. Phys., 2009, 9, 9491-9522.

52 A. Saleki-Gerhardt and G. Zografi, Pharm. Res., 1994, 11, 1166-1173.

53 H. P. Dette and T. Koop, J. Phys. Chem. A, 2015, 119, 4552-4561.

54 N. Smyrl and J. P. Devlin, J. Phys. Chem., 1972, 76, 3093-3094.

55 G. Pollard, N. Smyrl and J. P. Devlin, J. Phys. Chem., 1972, 76, 1826-1831.

56 K. Consani, J. P. Devlin, A. Ray, H. Farrar and E. W. Wilson, J. Chem. Phys., 1981, 74, 4774-4779.

57 P. Wen, P. Harrowell and C. A. Angell, J. Phys. Chem. A, 2011, 115, 6260-6268.

58 C. A. Angell and D. B. Helphrey, J. Phys. Chem., 1971, 75, 2306-2312.

59 B. Zobrist, C. Marcolli, D. A. Pedernera and T. Koop, Atmos. Chem. Phys., 2008, 8, 5221-5244.

60 O. Pokluda, C. T. Bellehumeur and J. Vlachopoulos, AIChE J., 1997, 43, 3253-3256.

61 S. S. Petters and M. D. Petters, J. Geophys. Res.: Atmos., 2016, 121, 1878-1895.

62 G. Bertozzi and G. Sternheim, J. Phys. Chem., 1964, 68, 2908-2912.

63 A. Baldelli, R. M. Power, R. E. H. Miles, J. P. Reid and R. Vehring, Aerosol Sci. Technol., 2016, 50, 693-704.

64 B. B. Wang and A. Laskin, J. Geophys. Res.: Atmos., 2014, 119, 3335-3351.

65 I. N. Tang and H. R. Munkelwitz, J. Geophys. Res.: Atmos., 1994, 99, 18801-18808.

66 H. Kim, M. J. Lee, H. J. Jung, H. J. Eom, S. Maskey, K. H. Ahn and C. U. Ro, Atmos. Environ., 2012, 60, 68-75.

67 N. K. Richards, L. M. Wingen, K. M. Callahan, N. Nishino, M. T. Kleinman, D. J. Tobias and B. J. Finlayson-Pitts, J. Phys. Chem. A, 2011, 115, 5810-5821.

68 Q. N. Zhang, Y. Zhang, C. Cai, Y. C. Guo, J. P. Reid and Y. H. Zhang, J. Phys. Chem. A, 2014, 118, 2728-2737.

69 R. H. Stokes and R. A. Robinson, J. Phys. Chem., 1966, 70, 2126-2130. 